\title{
100-year-old Haematologica images: the origin of megakaryocytes
}

\section{Carlo L. Balduini}

Ferrata-Storti Foundation, Pavia, Italy

E-mail: CARLO L. BALDUINI - carlo.balduini@unipv.it

doi:10.3324/haematol.2020.262873

S ome of the covers of recent issues of Haematologica were dedicated to the origin of platelets, ${ }^{1-3}$ one of the most hotly debated topics at the time the Journal was founded. Another subject of much discussion was the origin of megakaryocytes, the "giant bone marrow cells" discovered by Giulio Bizzozero in 1869. ${ }^{4}$ Most authors, including Adolfo Ferrata and Alexander A. Maximow, speculated that these cells derive from the common progenitor of all hematopoietic lineages ('Emoistioblasto di Ferrata' or stem cell) and that their multinuclearity is the consequence of nuclear divisions without subsequent cytodieresis. However, other authors thought differently. The image of the cover of this issue of the Journal has been taken from an article entitled "About the system of bone marrow giant cells" published in Haematologica by Giovanni di Guglielmo in 1925 (Figure 1). The author, at that time a young assistant to Ferrata at the Department of Medicine of the Pavia University Hospital, investigated the bone marrow of several animals both in the prenatal and postnatal periods and concluded that megakaryocytes derive from the Emoistioblasto di Ferrata, and that their multinuclearity is the consequence of the fusion of two or more of these elements. Di Guglielmo, who three years later would go on to publish his ground-breaking work on acute erythremic myelosis (now known as pure erythroid lenkemia), ${ }^{6,7}$ was wrong about the origin of the multinuclearity of megakaryocytes, but the beauty of the color plates that illustrate his article still amaze us. I think it is worth noting that Ferrata, who at the time was Editor in Chief of Haematologica, agreed to publish Di Guglielmo's article despite the fact that his pupil had arrived at conclusions that he did not share. Respect for the opinions of others, including those of his assistants, was an important characteristic of this old master of hematology.

\section{References}

1. Balduini CL. 100-Year Old Haematologica Images: The Quarrel about the Origin of Platelets (I). Haematologica. 2020;105(5):1169.

2. Balduini CL. 100-Year Old Haematologica Images: The Quarrel about the Origin of Platelets (II). Haematologica. 2020;105(6):1467.

3. Balduini CL. 100-Year Old Haematologica Images: The Quarrel about the Origin of Platelets (III). Haematologica. 2020;105(7):1751.

4. Bizzozero, G. [Sul midollo delle ossa]. Il Morgagni. 1869;11:617-646.

5. Di Guglielmo G. [Sul sistema delle cellule giganti midollari]. Haematologica. 1925;6:156-195.

6. Di Guglielmo G. [Le eritremie]. Haematologica. 1928;9:301-347.

7. Balduini CL. 100-Year Old Haematologica Images: Di Guglielmo Disease or Pure Erythroid Leukemia. Haematologica. 2020;105(3):105.
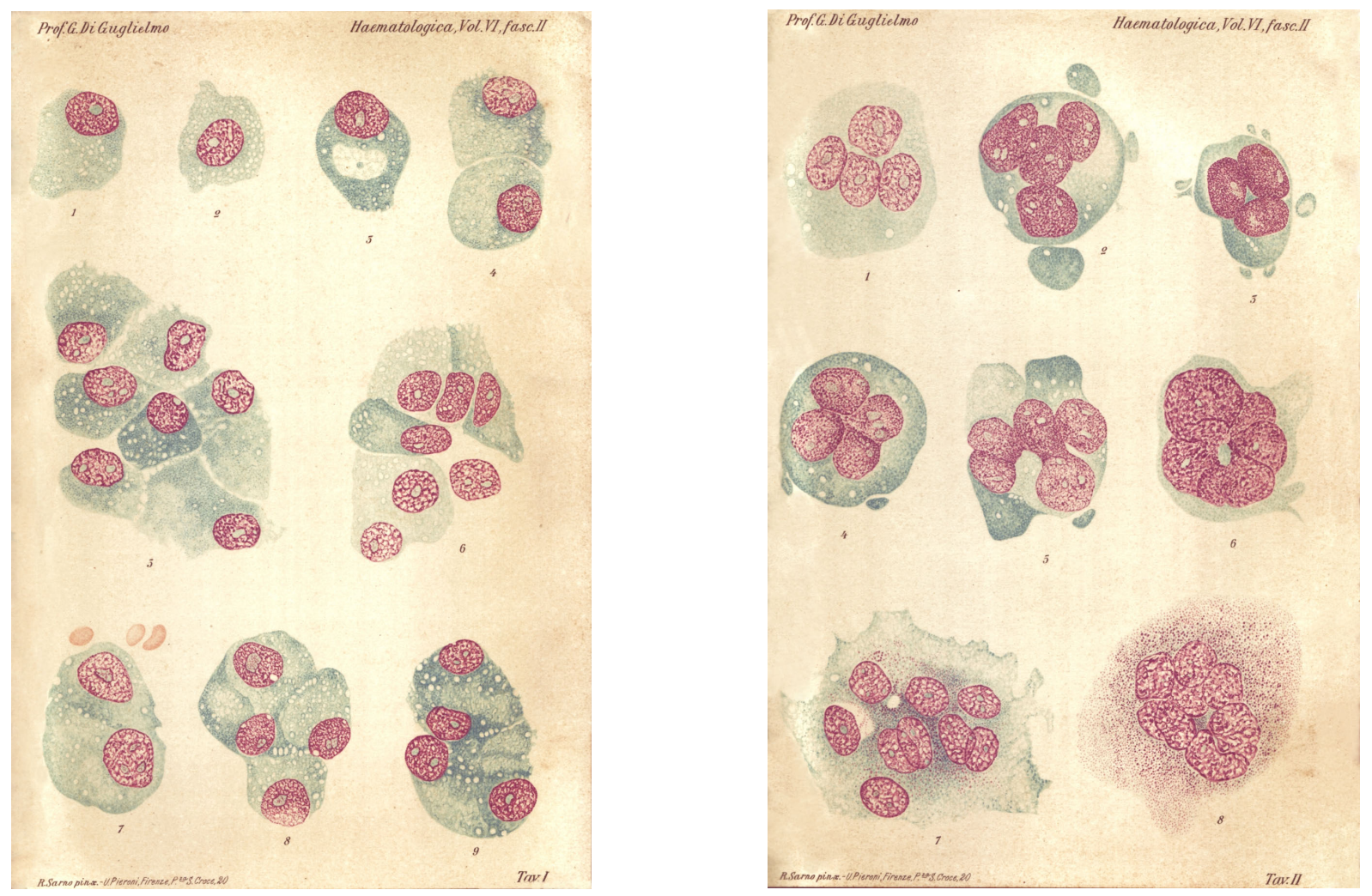

Figure 1. The origin of megakaryocytes. The images reproduce the hand-drawn color plates illustrating an article published in Haematologica by Giovanni Di Guglielmo in 1925 , in which he suggested that megakaryocytes derive from common hematopoietic progenitors that merge and give rise to multinucleated giant cells. 